\title{
Model Building of "Four Learning" Distance Teaching Mode Based on Cloud Computing Environment
}

\author{
Degang Lai \\ Southwestern University, Chongqing, 400715, China
}

Keywords: Cloud computing. "Four Learning". Distance teaching. Model building

\begin{abstract}
The main contents of "Four Learning" are: assist learning, guide learning, and promote learning and willing to learn. This learning model belongs to remote open teaching mode, which can promote students' learning awareness, improve their interest in learning, bringing students more convenient, alternative methods of learning. This paper by studying the "Four Learning" model of one school, try to understand the advantages of this high-tech teaching method, and summarize the teaching effect brought by this learning environment.
\end{abstract}

\section{Introduction}

Cloud computing environments are characterized by the use of computer and Internet to reveal the knowledge which students have learned, which bring students into a new world of knowledge through virtual methods and this method can enhance students' memory and learning efficiency. The requirements of "Four Learning" to students also meet characteristics of cloud computing environments. Thus the cloud computing system can better serve the students, providing a clear knowledge structure, building a modern student-centered learning model. Computer technology is in a stage of rapid development, so using technology, the studying under cloud computing environment is gradually changing to diversify, for example, students can build their own learning platform through their own ideas, creating their own learning atmosphere and style, but also help to achieved "Four Learning".

\section{Discussion on carrying out "Four Learning" in cloud computing}

\section{The application of "Four Learning" in cloud computing environment}

The popularity of cloud computing technology provides a good opportunity for knowledge popularization. The technology carries distance education platform which can make perfect convergence of students and knowledge, and also can realize the common sharing of educational resources, bringing students into a free learning, autonomous learning space, also complies with new requirements of new technology revolution. For the universities in our country, this kind of teaching environment should be carried out and implemented, to understand the cloud computing technology, integrating distance education into the higher education system. Cloud computing technology can become a cornerstone of education, on this basis build the distance education service platform, to realize the "Four Learning", that is, assist learning, guide learning, and promote learning and willing to learn., and finally set up the education system with Chinese characteristics.

\section{Basic features of cloud computing model}

\section{With own system of educational services}

In the cloud computing system, knowledge is interrelated and cut-through, each course has its own teaching resources and own system, and the system is under unified management and deployment. For university teachers, they can make use of virtualization technology, to sufficient conduct and share knowledge. The educational services are open, transparent and free for every student.

\section{Education services are flexible}

Cloud computing system can be changed, and it is changed (flexible) at any time with the students' demand for knowledge and system review. For example, students add their own professional knowledge through course teaching, then at the same time they also can know the contents 
corresponding to their own occupation planning. Thus, at the same time of learning, they also can make preliminary plan for their own future, but also can prevent the cloud server load being too large and the service quality declining, and even emergence of resources lost situation.

\section{Operation per knowledge demands}

Students can get unlimited knowledge reserve from cloud computing system, such as data, applications, course record, etc. The system can also according to students' demands for knowledge develop their own learning plan which fit them. The fully automated management and service has been achieved, compared with manual services intervention, it has higher efficiency.

\section{Advantage of cloud computing environment in talent cultivation}

In the cloud computing system, Internet technology is essential. Only those with good network technology, it can guarantee the knowledge points timely and accurately transmitted to students, to achieve assist learning, guiding learning, promoting learning and willing to learn. Cloud computing system can adapt to the current Internet, applying high technology to bring high school education resources advanced knowledge transportation way. The above advantages are also several aspects need to be supplemented in higher education of China.

\section{Students' demand for cloud computing system}

For the students, the interesting learning styles should be in convenient and direct, and therefore the cloud computing system is able to fully meet the needs of students, but also making students more willing to learn, thus students will be able to autonomic learn in more free and relaxed environment, and a wider range of choice, and students are more interested in the program. Therefore, students' demand for cloud computing also reflects the requirements of education technicalization, and universities take advantage of the system is also a necessary requirement of the development of times.

\section{College teaching demand for cloud computing systems}

For university teachers, the use of cloud computing system in teaching is more flexible, for example. For example, teachers can teach courses in different areas at any time, greatly improving the efficiency of teaching; teachers can through system teach remotely, to minimize the consumption of useless time, but also can achieve one-to-many, many-to-many teaching ways to ensure the quality of teaching. With the integration of intelligent system, the "Four Learning" model in cloud computing technology environment has irreplaceable advantages compared to traditional teaching methods. The traditional teaching method applies monorail service and lack of teaching resources, the teacher-student interaction is difficult to achieve, slow to promote knowledge, and students do not have keen interest; but the teaching service of cloud computing system overturns it completely, and ultimately demand of willing to learn has been achieved.

\section{The practical application in teaching of the "Four Learning" in cloud computing environment}

Through the research on the application of cloud computing platform in university teaching, and the exploration of its close connection with "Four Learning", it can be known that the cloud computing platform system is able to effectively treat and complete the leftover problems from the previous teaching, bringing teachers and students a kind of innovation of knowledge dissemination, and both teachers and students have high evaluation to the system.

\section{Main contents of "Four Learning"}

Through research it can be known that the contents of "Four Learning" in cloud computing system as: the teacher's role is to guide, assist and supervise students to learn; teachers have done these three points, then they can guide students through the platform to learn distance learning, giving fully play the advantages of digital system and multimedia to communicate, and thus the foundation objective will be able to achieved; in addition, cloud computing system can also lead students to experience richer learning contents, and it is gradually optimized the traditional passive learning to enjoy learning, learning is no longer considered the burden, seeking happiness in it.

The guide to learn in "Four Learning" has meaning of the following layers: First, with the cloud computing platform to drive students to learn, to find the learning state in time, for example, through the Internet platform to do courses selection, registration, after class discussions, and teachers are 
able to answer students' questions anytime and anywhere; Second, the forms of class composition are diversified, that teachers are able to teach in a remote manner to check students' classroom tasks, understand student learning, and mark exercises and papers at any time, to achieve efficiency improvement. The assist to learn in "Four Learning" is mainly refers to teachers can demonstrate practices to students directly through the platform, besides solving the problem of students in learning, and it can also establish the concept of active learning, teaching the learning methods, guide students to learn from a macro perspective. The promote to learn in "Four Learning" mainly refers to teachers take the cloud computing system as the carrier, urging students to study hard. For example, teachers can use software to know students' learning status and supervise them, the commonly used software includes Zoho Wiki, Zoho forums, etc. through the use of their own unique active teaching methods to help students overcome their learning difficulties. The willing to learn in "Four Learning" mainly refers to teachers should establish a "joyful learning" thinking for students, concept of "learning to achieve self-worth", to ensure that students establish right learning value, be more proactive in learning, changing the past passive learning to active learning, willing to learn; For example, teachers can show excellent works by the cloud computing system to students, to improve their interest and guide students to complete study together, experiencing the fun of learning brought by computer technology.

\section{Building of "Four Learning" in cloud computing system}

In traditional teaching system, the teacher is the first one, playing a role of leading and guiding, but in the cloud computing system, students are the subject of learning, the first three of "Four Learning" are for the final willing to learn. The relationship between the four items can make students establish correct concept of learning, gradually transforming the traditional autonomic learning into students' conscious behavior and develop good study habits. By understanding it can be known that the relationship between teachers and students is not unidirectional, but influencing each other, interacting. For example, in the "Four Learning" model, teachers can understand students' learning, so as on this basis adjust their teaching programs, and students can actively participate in the study, and gradually establish the objective of "ready to learn".

\section{The practical application of the "Four Learning" in cloud computing system}

Make "Four Learning" in the cloud computing system established in place, the distance learning mode mainly on "guide to learn, assist to learn, promote to learn and willing to learn" can be gradually established, only integrated the cloud computing system with the "Four Learning", the effective operation of university teaching system is ensured. Most of our colleges and universities have a number of computer education equipment, so it should be a reasonable application, as below.

\section{Establish "Four Learning" dynamic group learning system}

The teaching contents received by every student are different, so teachers should focus on the characteristic develop study group with different subjects and contents. The group members can help each other, and assist to learn. For example, when explaining the contents of courseware, teachers can prepare courseware and show and share to each group; each group is able to understand the making process of courseware and problems that need attention, so that it can be ensured for students' learning dynamic, to complete the learning of courseware and actual making with the fastest speed.

Make full use of the advantages of computer technology to build "Four Learning" mode

Compared with the traditional classroom teaching, the teaching mode cloud in computing system has its own characteristics. Such as the teaching structure is complex, teachers need to know students' proficiency in computer technology in the implementation of teaching; the following questions need to be taken into consideration: students' major, students' receptivity, students' different learning environment and students' learning habits, etc. By understanding these issues, teachers should constantly develop new teaching objectives, design and develop diversified teaching policies, develop proper evaluation mechanisms with reference to different learning conditions; such a cloud computing system is really valuable, suitable for achievement of "Four Learning" objective.

\section{Popularity of the use of terminal equipment of cloud computing}


Cloud computing terminal equipment mainly includes the terminal systems for building cloud computing and mobile phones and other smart devices. Through understanding the statistics of China's internet users released by China Internet Center, it can be seen that in China's Internet users, nearly $75 \%$ of the population are mobile phone users, and the data is still rising. For this reason, the popularity of cloud computing system can take the mobile phone users as carrier, students can go through mobile learning by mobile phones which with higher utilization rate, greatly improving the interest in learning. It is a valid measure of "Four Learning" popularity.

The achievement of objective from interest to awareness to active learning requires assist of cloud computing system

Interest, awareness, active learning directly correspond to the "assist to learn, guide to learn and promote to learn" in four learning. The ultimate goal is to guide students "willing to learn". Teachers can through the teaching objectives in "Four Learning", upload the teaching content to share with the cloud computing system software. Students are able to access to educational technology and the latest science and technology at first time students, and use their own creation to make learning environment belong to them, to experience the success and joy of learning, and ultimately achieve "willing to learn."

\section{Reform of higher education, assessment}

In the early 30 years ago, China had begun to try and use the distance education mode, but the assessment mechanism of university still had no major changes. For example, colleges and universities require students promptly return to school for final examination; and the examination time is usually up to a week, which causes some impact on students' social practice and job application. If using cloud computing system, students can connect remote education assessment platform, through a series of fingerprint, facial identification and other ways to ensure students complete appointment and assessment on time. Teachers also can real time monitor and supervise students' assessment through cloud computing system. It not only plays a supervisory role for students to have a more favorable assessment, but also can avoid students' trudge, to shorten the examination cycle and achieve cost savings. Cloud computing systems can improve the higher education and assessment to high, to facilitate the accomplishment of the "Four Learning", making the education system more efficient.

\section{Conclusion}

To sum up, cloud computing has a great role in promoting education of colleges and universities in our country, and it can provide useful information and the new development direction for our country's education. "Four Learning" is the new plan for the education concept in the new period. Only to ensure the students' main position in learning, can teachers assist learning, guide learning and enhance learning, finally to ensure that students are willing to learn and the cloud computing teaching system can be established. For the advantage of cloud computing, colleges and universities in our country should increase the openness of the education resources and absorb the advantageous teaching resources both at home and abroad, making the promotion and sharing of the "Four Learning" from the pilot to the national places. Only in this way, teaching resources and data can be fully utilized, also can establish platform contact between schools to improve the education competitive ability, also can make stable teaching quality and improve teaching efficiency of colleges and universities in our countries.

\section{Acknowledgments}

This article is the project of Southwestern University "Central Universities Fundamental Research Funds " (XDJK2012C105). 


\section{References}

[1] Yu Jianhua: Building mode of Distance teaching resources based on cloud computing -- take Zhejiang Open University for example, China Audio-Visual education, 2011 (12): 130-135.

[2] Yue Hao, Wang Xiaochu, Xu Lijie: Primary exploration on the construction of shared teaching resources pool of higher vocational colleges based on cloud computing environment, Journal of Shazhou vocational college of engineering, 2011,14 (3): 14-17

[3] Bi Ye, Zhu Huisheng: Design and achieve streaming media courseware generation system based on Windows Media technology, Computer System Application, 2009,17 (9) :15-18.

[4] Zhang Chunming: Study on the distance education system based on cloud computing, Computer CD-ROM software and applications, 2011, (4) :178-178.

[5] Liu Xiaogang, Xu Hongli: Exploration on the application of cloud computing in distance education system, Modern Distance Education, 2010, (5) :64-67.

[6] Wang Lei: Construction of new network teaching platform in cloud computing era, Heilongjiang Education (higher education research and evaluation edition), 2013, (1): 23-24 